\title{
RELATOS DE INFANCIAS: NACER Y VIVIR EN LAS VILLAS DEL SUR GLOBAL CARTOGRAFÍA Y DEVENIR DE LA SUBJETIVIDAD EN LAS SOCIEDADES CONTEMPORÁNEAS ${ }^{1}$
}

\author{
MERCEDEs MACHADO ${ }^{2}$ \\ LUCIANO MARTÍN MANTIÑ̃́N ${ }^{3}$ \\ SILVIA GRINBERG ${ }^{4}$
}

\begin{abstract}
RESUMEN
A través de una investigación de base etnográfica, donde recuperamos relatos de jóvenes que nacieron y viven en contextos de extrema pobreza urbana de la región Metropolitana de Buenos Aires, nos proponemos reflexionar acerca del devenir de la subjetividad en los barrios más pauperizados del sur global. Se trata de adentrarse en las múltiples conexiones, entendiendo que la realización de una cartografía no supone un calco, sino atravesar las diversas líneas de ese entramado. Proponemos discutir resultados de investigación acerca de la complejidad del nacer y vivir, procurando expresar algunos de los trazos que la infancia adquiere en los bordes de nuestra urbanidad.
\end{abstract}

\section{Palabras Clave: Infancia, Subjetividad, Pobreza Urbana}

\section{RELATO DE INFÂNCIAS: NASCER E MORAR NOS BAIRROS POBRES DO SUL GLOBAL}

\section{CARTOGRAFIA E DEVIR DA SUBJETIVIDADE NAS SOCIEDADES CONTEMPORÂNEAS}

\begin{abstract}
RESUMO
Através de uma pesquisa de base etnográfica, onde recuperamos relatos de jovens que nasceram e moram em contextos de extrema pobreza urbana da Região Metropolitana de Buenos Aires, visamos reflexionar sobre o devir da subjetividade nos bairros mais pauperizados do sul global. O objetivo é aprofundar nas múltiplas conexões entendendo que a realização de uma cartografia não supõe uma cópia, senão atravessar as diversas linhas dessa rede. Propomos discutir resultados de pesquisa sobre a complexidade do fato de nascer e morar, procurando expressar alguns dos traços que a infância adquire nas margens de nossa urbanidade.

$$
\text { Palavras - Chave: InfÂncia, SubJetividade, Pobreza Urbana. }
$$

\footnotetext{
${ }^{1}$ Este trabajo se enmarca en los proyectos de investigación del Centro de Estudios en Desigualdad, Sujetos e Instituciones

${ }^{2}$ Argentina. Licenciada en Ciencias de la Educación, Becaria doctoral CONICET/ CEDESI-EH, Universidad Nacional de San Martín/ Buenos Aires, Argentina/ mercedeslmachado@gmail.com.

${ }^{3}$ Argentino. Licenciado en Antropología Social y Cultural, Becario doctoral CONICET/CEDESI-EH, Universidad Nacional de San Martín/ Buenos Aires, Argentina/1mmantinan@yahoo.com.ar

${ }^{4}$ Argentina. Doctora en Educación, Investigadora CONICET/CEDESI-EH, Universidad Nacional de San Martín/ Buenos Aires, Argentina/ grinberg.silvia@gmail.com
} 
Última DÉCADA N²4, PROYECTO JUVENTUDES, DiCIEMBRE 2016, PP. 140-157

\title{
CHILDHOOD STORIES: TO BE BORN AND LIVE IN GLOBAL SOUTH SLUMS CARTOGRAPHY AND EVOLUTION OF SUBJECTIVITY IN CONTEMPORARY SOCIETIES
}

\begin{abstract}
On the basis of an ethnographic-oriented research, where we retrieved stories from young people born and raised in extremely poor urban contexts of Region Metropolitana of Buenos Aires, Argentina, we reflect on the development of subjectivity in the poorest towns from the global south side. We get deeper into the multiple existing connections, understanding that mapping such connections is not about copying but about crossing the diverse lines of that network. We propose a discussion on the research results concerning the complexity of being born and living in these places, ensuring an expression of some traces acquired by childhood in the skirts of our urbanity.
\end{abstract}

Keywords: Childhood, SubJectivity, Urban Poverty.

\section{INTRODUCCIÓN}

Deleuze y Guattari (2004) refieren a la cartografía como aquella práctica que supone al mapa y al diagrama. Dibujar la forma, los mecanismos del poder cuando se espacializan así como las máquinas que dejan al descubierto y abren vías de posible resistencia. El mapa, señalan los autores "es conectable en todas sus dimensiones, desmontable, alterable, susceptible de recibir constantemente modificaciones" (2004: 18). En este artículo, a través de relatos de jóvenes que viven contextos de extrema pobreza urbana en el área metropolitana de Buenos Aires (AMBA), nos proponemos ofrecer elementos para la descripción del devenir de la subjetividad, atendiendo a los trazos de ese nacer y vivir en los barrios más pauperizados del sur global. En la realización de esta cartografía se entiende que ella no supone un calco, sino más bien requiere atravesar las múltiples conexiones. Asimismo, cabe señalar que no se trata de la pregunta por la infancia en general, sino específicamente por el devenir de las infancias en los asentamientos precarizados (Cravino, 1999; Davis, 2007; Grinberg, 2012; Merklen, 2005; Ratier, 1985). Sin embargo, ello involucra entender que se trata de agenciamientos que son siempre individuales y colectivos. De forma que en los relatos de infancia nos encontramos con la historia vivida, realizada, aceptada y luchada por los jóvenes en los emplazamientos más pobres de la urbe metropolitana. Desde ya queda abierta para otros trabajos la pregunta por los modos en que esos relatos se articulan, contestan y ensamblan con/entre otros espacios de la urbe metropolitana.

El presente artículo se enmarca en los debates propios de los estudios sociales de la infancia y la juventud (Groppo, 2015; Castillo-Gallardo, 2015; Ierullo, 2015; Gómez-Mendoza y Alzate-Piedrahíta, 2014; Duarte-Duarte, 2013), entendiendo que constituyen una trama compleja que ensambla diversas perspectivas y disciplinas que hacen de estas categorías un espacio de múltiples significados (Llobet, 2011; Carli, 2002). Dentro de este campo nos encontramos con un primer grupo de investigaciones que refieren a los debates sobre la inclusión y 
exclusión social, marginación, segregación urbana, desigualdad y pobreza urbana (Minujin, 2006; Bustelo, 2007; Saraví, 2006; Mateos, 2006; Llobet et al., 2002; Litichever, 2008; Pojomovsky et al., 2008; Gentile, 2007; Macri y Ford, 2005). Un segundo grupo refiere a las instituciones de tutela y protección social (Zapiola, 2008; Cosse, 2005; Aversa, 2008; Cowen, 2005; Billorou, 2008). Otro grupo se concentra en los procesos de construcción e institucionalización de discursos y prácticas en relación con los aspectos pedagógicos, psicológicos, sanitarios, de derechos o protección integral (Carli, 2006; Llobet, 2009; Zapiola, 2006; Daroqui et al., 2007).

En este marco de debates, procuramos escapar a la tentación del pensamiento binario y de las dicotomías para la comprensión del devenir de la subjetividad, de las infancias en estos barrios. Seguridad y criminalidad (Auyero y Berti, 2013; ScheperHughes, 1993; Lewis, 1983) por un lado, pero también una cierta romantización de la vida en estos barrios que películas como Slumdog millonaire expresan con claridad (Hicky Moody, 2013; Roy, 2011; Arabindoo, 2011), se diluyen en el hacer y vivir diario de estos jóvenes (Grinberg y Dafunchio, 2016). Es la yuxtaposición, lo contradictorio y las tensiones aquello que aparece en los relatos de los/as jóvenes: "habrá que apoyarse directamente en una línea de fuga que permite fragmentar los estratos, romper las raíces y efectuar nuevas conexiones" (Deleuze y Guattari, 2000: 20). Esto adquiere centralidad por muy diversos motivos. Desde ya porque involucra una mirada conceptual, pero también porque se vuelve clave cuando la investigación intenta adentrarse en las líneas de fuerza que implican a la subjetivad, donde se solapan, entrecruzan y pujan los surcos de la subjetividad. Asimismo, cobra relevancia acercarse a la comprensión de las infancias y juventudes, procurando escapar tanto del énfasis en los mecanismos de sujeción asentados en la lógicas que Grignon y Passeron (1991) llamaron domino-centrismo, como también de las actuales lógicas gerenciales que proclaman el empoderamiento y la promoción de una agencia a la vez voluntariosa y virtuosa (Osborne y Rose, 1999; Grinberg, 2008). Los relatos de los/as jóvenes que nacieron y/o se criaron en las villas del conurbano bonaerense, se producen de modo quebrado entre la tensión que involucra nacer y vivir en aquellos barrios, que condensan y cristalizan en el espacio urbano todos los efectos de la creciente desigualdad metropolitana del sur global.

Nos preguntamos así, a través de los relatos de infancia, por el devenir de la subjetividad en aquellos espacios urbanos caracterizados por la extrema pobreza y la degradación ambiental. Ello, metodológicamente, implica encontrarse con los peros y los posibles; esto es con aquello que contradice las imágenes que comúnmente se proyectan sobre estos espacios. Se procura un tipo de comprensión sobre aquello que se bifurca, ofreciendo líneas para pensar de otro modo, más allá de las dicotomías y las certezas. Ello porque en el trabajo de investigación, nos encontramos de modo permanente con relatos e historias de vida que se construyen y se hacen posibles en esos trazos que siempre son discordantes. Así, por ejemplo, la villa se realiza como la posibilidad de tener un hogar y por tanto es querida, valorada y afirmada. Pero también ese tener un lugar, es parte de la espacialización de los mecanismos de poder constitutivos de las metrópolis del sur global desde fines del siglo XX, que crecieron al calor de los procesos de metropolización selectiva propios de estos tiempos gerenciales (Prevot-Schapira, 2001; Arabindoo, 2011; Grinberg, 2011). Ambos aspectos son objeto de la narración de ese nacer y vivir en estos asentamientos. Son esas tensiones las que en este artículo permiten adentrarnos en las particularidades que atraviesan las infancias, tensiones que refieren al entramado en el cual las subjetividades se tramitan. 


\section{ASPECTOS METODOLÓGICOS}

A través de entrevistas de tipo biográfico (Ramírez-López, 2014; Guber, 2001; Mallimaci y Giménez Beliveau, 2006) realizadas con jóvenes que nacieron -y/o se criaron- y viven en contextos de extrema pobreza urbana, describimos las líneas que se ensamblan en el devenir de las infancias en las sociedades contemporáneas. Entendemos que todo agenciamiento es básicamente territorial y reclama por un territorio en particular (Fox y Alldred, 2015). Esto adquiere especial sentido en las villas, porque ellas son resultado de las luchas por tener un lugar, del agenciamiento colectivo que pone en marcha procesos de urbanización, así como de las formas que presentan las políticas sobre la vida en tiempos gerenciales (Grinberg, 2008). A lo largo de dichas entrevistas, nos encontramos con textos que, como redes, ensamblan, afectan y son afectados por un territorio producido y resultado de las luchas por tener, valga la redundancia, lugar. Esto reclama una historia del presente donde esas infancias, el devenir de la subjetividad, involucra los modos históricos de afectar y ser afectados, que son los que se entretejen en sus relatos biográficos (Foucault, 2001).

Este artículo tiene como punto de anclaje el trabajo etnográfico que realizamos en la intersección escuela-barrio, en uno los barrios que en Argentina comúnmente reciben el nombre de "villas miseria". Específicamente el trabajo se desarrolló en el barrio Carcova, localizado en José León Suárez, Partido de General San Martín Provincia de Buenos Aires. En este barrio viven los/as jóvenes con quienes trabajamos. Estos asistieron o asisten a las escuelas en las cuales desarrollamos las acciones de investigación. Se trata de dos escuelas de educación secundaria, que si bien se encuentran localizadas a una distancia de 20 cuadras entre sí, comparten una población estudiantil que habita en esos barrios.

El trabajo involucra la comprensión compleja del contexto local, a la vez que la asunción de una posición, valores sobre los hechos que se presencian y sus múltiples registros (Das, 2003). Asimismo y desde un enfoque etnográfico postestructuralista (Choi, 2006; Youdell, 2006; Ringrose and Coleman, 2013), realizamos el trabajo de campo procurando hacer una historia del presente que no es igual a la experiencia vivida con sus singularidades, pero tampoco refiere a un universal en el cual los sujetos se diluyen (Deleuze, 2007). Se trata del estudio de los eventos en la cotidianeidad, de los desvíos, la historicidad rota (Cole, 2013; Grinberg, 2013).

El trabajo de obtención de información que aquí se discute involucra la realización de quince entrevistas de tipo biográficas (Ramírez-López, 2014; Guber, 2001; Mallimaci y Giménez Beliveau, 2006) a jóvenes de entre 17 y 22 años, durante el primer cuatrimestre de 2015. A través de estos relatos procuramos recuperar la historia familiar y las experiencias de infancias de lo/as entrevistado/as, volviendo sobre los recuerdos que tienen acerca de cómo se establecieron, así como del devenir sujeto en estos espacios de la urbe.

Asimismo, recuperamos cuentos escritos por niños/as en una de las escuelas emplazadas en el barrio a partir de una actividad áulica. En estas escuelas desde hace seis años venimos trabajando e interviniendo de diversas formas y con distintas actividades. Entre ellas cabe mencionar talleres audiovisuales, registros fotográficos en las escuelas y

\footnotetext{
${ }^{5}$ El término "villa miseria" fue acuñado por el periodista Bernardo Verbistsky en su novela titulada Villa Miseria también es América (1957). Luego es Hugo Ratier (1985) quien se ocupa de rastrear el origen de éstas en Argentina.
} 
por uno de estos barrios, micros radiales sobre temáticas vinculadas a la cuestión ambiental, trabajo con cuentos y narración oral, construcción de mapas barriales donde se recuperan experiencias y significaciones de los espacios, etc.

A partir de estos registros, nos detuvimos en el análisis de aquello que los jóvenes expresan acerca de sus experiencias de infancia. Entendemos por un lado que el trabajo de campo etnográfico (Cabrera, 2010; Guber, 2001; Rockwell, 2009; Althabe y Hernández, 2005; Peirano, 1995; Marcus, 2001) ofrece una multitud de oportunidades para explorar no sólo las formas que asumen dichas experiencias, sino también sus tensiones, fisuras, disonancias y ambigüedades.

\section{ACERCA DE LAS VILLAS MISERIA, LOS SLUMS DEL SUR GLOBAL: BIOPOLÍTICAS DE LA VIDA URBANA}

En los "bordes" de la ciudad, las villas se constituyen en torno a irregularidades de todo tipo que expresan particularidades del habitar en estos contextos y que no son posibles en otros espacios de la ciudad. Bordes que no remiten a la localización espacial, ya que muchos de estos barrios se encuentran en los cascos céntricos de las metrópolis, sino más bien a la posición política. Bordes que definen espacios urbanos sin grandes avenidas que sirvan como corredores de aire, ni con disposición de servicios públicos del agua potable, cloacales, ni recolección de basura, entre otros.

Es en estos barrios donde la lógica de la gubernamentalidad "consistente en el 'dejar hacer', y el 'empoderamiento de la comunidad local' se expresa, quizá, en su forma más extrema y perversa" (Grinberg, Gutiérrez y Mantiñán, 2012: 156); donde la provisión de servicios públicos es garantizada de modo precario por la intervención estatal. No adscribimos a las hipótesis que refieren a una ausencia estatal, todo lo contrario, se trata de la forma que adquiere esa presencia en estos barrios, presencia que se efectiviza a través de la lógica del empoderamiento de la comunidad (Rose, 2007; Grinberg, 2008).

Estos espacios urbanos, en su gran mayoría, se construyeron sobre aquello que hace algunas décadas eran espacios verdes deshabitados y/o baldíos, que paulatinamente fueron cubriéndose con basura que sirvió para rellenar el bañado, volviéndolo de esta manera posible de ser edificado. Hoy aquello que se ve, son espacios densamente poblados, con casas de construcción muy precaria inicialmente construidas con materiales recuperados, como chapas, alambres, recortes de madera, nylon, etc., y que permanentemente son mejoradas con ladrillos y cemento. Mayoritariamente, dada la precariedad de la condiciones de la urbanización, las construcciones se amontonan a lo largo de estrechos pasillos que en muchos casos son atravesados por arroyos y afluentes de los ríos más importantes de la urbe.

Aquí, nos importa menos el relato y/o descripción de las condiciones de vida del barrio y más los modos en que éstas afectan y son afectadas; esto es los modos en que subjetividad y espacio urbano se ensamblan en el devenir de la infancia en estos enclaves de las metrópolis. Es desde este interés que a continuación, nos adentramos a través de los relatos de los jóvenes en esos múltiples nodos de la afectación.

\section{RELATOS DE INFANCIAS}

En este apartado ofrecemos algunos elementos para la comprensión del devenir de la subjetividad en las villas. A tal efecto presentamos la discusión a través de las categorías 
que construimos como resultado del análisis de la información obtenida y que entendemos, refieren a aspectos nodales del devenir de las subjetividades en estos espacios urbanos. Estas categorías son comprendidas aquí como aquellas "intensidades" (Deleuze y Guattari, 2004) que se presentan de modo recurrente en los relatos que los jóvenes nos hacen de sus historias vividas. Se trata de construcciones analíticas nacidas del trabajo de campo que nos permiten trazar un recorrido, una cartografía que hace a la vida de los jóvenes en estos contextos. En el trabajo de análisis primero focalizamos en algunos aspectos comunes y puntos nodales de las historias que constituyen aquellas intensidades, para luego entramarlas en el recorrido que aquí planteamos. En lo que sigue entonces, proponemos un acercamiento a la comprensión de estas intensidades a través de las siguientes categorías: a) buscar y tener lugar, remitiendo a las experiencias del nacer/ llegar, establecerse y criarse en estos barrios, a aquellos relatos del moverse y trasladarse en búsqueda de un lugar; b) vivir en/el borde, refiriendo a las tensiones del vivir en estos espacios, donde se conjugan el juego y el miedo, la diversión y la peligrosidad, términos que no son opuestos sino que se entraman en una red de experiencias y significaciones que hace a la vida, escapando de las miradas simplistas y dicotómicas; c) llegar a ser alguien, donde recuperaremos los deseos, los sueños y temores que se movilizan y tensionan cuando en el presente piensan el futuro. Cada uno de estos ítems es abordado en sub-apartados que se inician con un relato de los jóvenes. Elegimos a cada uno porque creemos condensan la complejidad de devenir sujeto en las villas. Asimismo, aquello que nos importa es ofrecer una problematización de ese devenir. Ello entendiendo que la tarea de la investigación no consiste en resolver lo discordante, sino más procurar un análisis que permita comprender qué es aquello que hace posible que ese problema ocurra. Esto es: procuramos mucho más problematizar ese devenir de la subjetividad en las villas, que reconstruirla ofreciendo o devolviendo alguna lógica explicativa (Rabinow, 2003). Con esta intención nos adentramos en el análisis del material de campo en los siguientes tres puntos.

\subsection{Buscar y tener lugar}

Cuando mi mamá tenía alrededor de doce años vinieron para acá (...) después nos fuimos a Mitre, Mitre y Gascón, Carcova, Villa Hidalgo, por todos lados. (mujer, 17 años)

Una de las principales recurrencias que encontramos en los relatos, como el que funciona aquí de epígrafe, fue la presencia de la migración que atraviesa de modos diversos a las familias. Las situaciones de migración forman parte de las historias familiares que relatan los jóvenes en las entrevistas. Este es el caso del relato que realizan respecto de cómo llegaron sus padres/madres y abuelos/as, y que otras veces es reactualizado en sus propias vidas cuando relatan su propio moverse entre diferentes barrios. En ambos casos, la idea del moverse, establecerse y volver a trasladarse se presenta como un eje que atraviesa el relato de sus infancias. En muchos de los casos, las familias se trasladan desde provincias del interior del país y/o países limítrofes, en general provenientes de espacios rurales. Esto no constituye algo nuevo del siglo XXI; la conformación de estos espacios urbanos durante el siglo XX se remonta a las grandes migraciones poblacionales que se produjeron desde aquellos espacios a raíz de las sucesivas crisis económicas, y que en particular se profundizan en sus últimas décadas (Romero, 1986; Auyero y Swistun, 2008; Ratier, 1985).

Ahora bien, aquello que si aparece como algo propio de estas urbanizaciones es un tipo de migración que ocurre a través de múltiples traslados. Esto es, traslados que 
se escalonan en y través de diversos espacios que devienen en lugares transitorios de residencia hasta la llegada a un barrio que se vuelve residencia. Así señala una joven:

Estuvieron alquilando distintas casas hasta los diez años, de ahí me fui a Otamendi y después volvimos a este barrio (...) Porque alquilamos y los contratos son por dos años. (Entrevista, mujer, 18 años)

La idea del moverse, establecerse y volver a trasladarse constituye uno de los ejes claves para pensar la constitución de las infancias en estos espacios de la urbe. Las referencias remiten a quien no tiene lugar y se mueve para buscarlo:

Nos venimos acá a Argentina porque mi tía la llamó a mamá diciéndole que quería que viajara, porque la situación estaba media mal en Perú y bueno, tuvimos que viajar. (...) Y ¿cómo fue el cambio entre Perú y Argentina? Para mí fue complicado dejar mi familia. (Entrevista, mujer, 19 años).

Este caso grafica la situación de las familias que llegaron provenientes de países cercanos impulsados por diversos motivos entre los que predominan: la causa económica, conseguir trabajo, mejorarlo, mejorar las condiciones habitacionales, la esperanza de que los hijos no tengan que pasar por situaciones de precariedad y pobreza como las que ellos mismos pasaron. Así en esa misma línea otra joven relata:

Desde que nací estoy acá. Ah no, viví en Santa Fe hasta que cumplí un año y ya del año me vine para acá (...) Porque allá es un lugar donde no hay trabajo, plata, así... como que es un lugar más pobre. (Entrevista, mujer, 20 años)

En este como en los otros relatos, nos encontramos con la voz de jóvenes que expresan aquello que es un hito de los últimos cuarenta años de historia de la región y en cierta medida del sur global: el desplazamiento hacia los cascos urbanos buscando no sólo trabajo, sino un lugar donde vivir. La llegada al barrio vinculada con la cercanía a otros familiares, ocurre en procura de una mejora en la calidad de vida. Búsqueda de lugar que involucra dejar otro en el que ya no se puede vivir. Es por ello que, como narran los jóvenes, la llegada al barrio convive con la experiencia del desarraigo y la nostalgia por el lugar que se deja y los seres queridos, ahora lejanos. Es así como los movimientos de un barrio a otro, así como la llegada en sí a un barrio determinado suele estar asociada con los amigos y principalmente familiares que llegaron anteriormente allí:

Antes vivíamos en Colegiales. Y nos mudamos para acá. Porque acá estaba toda la familia y nos mudamos para acá por eso, creo yo. Mis dos abuelos, la mayoría, todos, mis tíos, mis primos, están todos acá. (Entrevista, mujer, 20 años)

No se trata de movimientos masivos sino más bien familiares donde uno va motivando al otro. Asimismo, es un moverse en la búsqueda de mejorar las propias condiciones de vida. A diferencia de otros sectores de la urbe donde desde ya la gente también se muda, la llegada a estos barrios no supone formas lineales. La búsqueda de lugar involucra desplazamientos sucesivos por diferentes tipos de asentamientos. Como lo 
describen en las entrevistas, la llegada al barrio ocurre luego de haber pasado por alquileres diversos dentro y fuera de las villas. Los relatos de los jóvenes dan cuenta de este recorrido en el cual cada espacio debe ser conquistado y donde incluso el lugar que ocupan, como se plantea más adelante, dista de pensarse como definitivo. Así, el siguiente fragmento remite ya no a como llegan a Buenos Aires, sino a los movimientos que realizan los padres de la joven entre las villas hasta que llegan a Carcova, lugar donde todavía viven con su familia:

Cuando ella estaba soltera después lo conoce a mi papá, fueron a alquilar a La Rana. Estuvieron un tiempo ahí y cuando se enteró de que acá en el barrio de Carcova (...) podían agarrar terrenos porque era un campo que la gente estaba tomando... Y ella como estaba en alquiler...así que no era vida porque ya creo que estaba embarazada ella, vinieron acá y tomaron el lugar. (Entrevista, mujer, 21 años)

En este último relato, nos encontramos con otra capa de la cartografía barrial. Se trata de una familia que alquilaba en otra villa (La Rana), y que encontró en Carcova la posibilidad de tomar un terreno y dejar de arrendar. La idea de tomar, de ocupar el espacio se vuelve la posibilidad de tener lugar. Una cierta violencia acompaña ese tener, cuando el único modo de obtenerlo es tomándolo. En éste como en otros relatos se repite ese "agarrar" y "tomar" un espacio para transformarlo en un lugar, para hacerse el propio lugar.

Interesa especialmente esa idea de tomar, agarrar, porque remite a una condición que es definidamente personal en tanto remite al propio lugar de vida, pero que a la vez es política. Esto es, ese tomar ocurre en un contexto en el cual los sujetos se ven obligados a dejar su lugar de vida, obligados a desplazarse y salir a la búsqueda de otro lugar. En los relatos de los jóvenes nos encontramos con la historia vivida, con los modos en que las políticas y lógicas gerenciales atraviesan y se ensamblan en el devenir de los barrios más empobrecidos del sur global. Se trata de las formas que asumen las políticas hacia la vida en las sociedades contemporáneas: "hacerse lugar" supone tomar, ocupar espacios baldíos, en general sobre tierras poco valuadas, terrenos fiscales, zonas de acumulación de desechos urbanos, basurales, zonas aledañas a ríos contaminados, donde terminan confluyendo la degradación ambiental, la falta de planificación urbana y la extrema pobreza. Esto es, en espacios que condensan la complejidad de las irregularidades que caracterizan la urbanidad contemporánea en el sur global. Son formas de la biopolítica contemporánea, que a la vez ofrecen herramientas para comprender la cara más mediática y, probablemente, más preocupante de la vida en las villas que es aquella ligada con la peligrosidad. Como puede observarse en el siguiente fragmento de entrevista, en los relatos de los jóvenes esa peligrosidad presenta diversos matices, entre ellos la experiencia del peligro, la cercanía con la muerte y el sentimiento de dolor:

Y que la gran mayoría ahora de los chicos están presos, están muertos, algunos se quedaron inválidos, la policía los mató (...) Y es triste, sí, es triste que en el barrio siempre hay muerte, es triste. (Entrevista, mujer, 21 años) 
Es a ello que hemos denominado vivir en el borde, pero también vivir el borde. Sobre ello nos ocupamos en el siguiente apartado.

\subsection{Vivir en/el borde}

Este barrio es muy peligroso pero está más o menos bueno. La escuela está buena, hay muchas profesoras buenas, mataron a muchos chicos de acá. En el zanjón tiraron mucha basura. Las plazas están re buenas, anoche estaban tirando tiros, estaba durmiendo pero se escucharon muy fuertes. (Cuento, varón, 13 años)

El relato que precede pertenece a un adolescente y fue registrado en la actividad mencionada en una de las escuelas. Lo trascribimos textual, respetando su puntuación porque creemos que así da cuenta de una de las principales tensiones que atraviesa políticamente la vida. En una misma oración todo se mezcla, el peligro y lo bueno, una buena escuela y profesoras, la muerte, la basura, los tiros y los espacios para jugar. Por esto mismo es que estas tensiones no remiten a polos opuestos sino a una trama de significaciones y experiencias que se constituyen como la vida en el borde. No se trata de tiroteos o juegos, sino que ambos definen al propio espacio. El texto continúa del siguiente modo:

Los chicos juegan a la pelota y la cancha está muy sucia y se divierten, les gusta la cancha, para jugar a la pelota. Junto a la cancha está el zanjón, los chicos tienen que tener cuidado jugando a la pelota. (Cuento, varón, 13 años).

Si bien todos los juegos tienen reglas y pautas, aquí se suman delimitaciones y precauciones asociadas al propio espacio en el cual cobra vida lo lúdico. Es a esa idea que denominamos vivir el y en el borde. No se trata de no jugar, sino de un modo que asume el juego cuando se es niño. Un borde que define que, como señala este niño, hay que tener cuidado porque se juega a la vera de un zanjón contaminado. En esa línea y desde otra perspectiva remite a otra cara de ese borde, como cuenta esta joven:

A mí lo que me hizo mal fue una muerte de un chico. Que a él lo mató la policía en Ballester, que fue a robar a un comisario (...) Yo me crié con el chico. Hará dos años ahora que falleció. Era un chico sufrido porque al papá también lo mató la policía. Y la madre, como ellos eran muchos hermanos... la madre se iba a trabajar, ellos quedaron con sus abuelas y casi siempre vivían en la calle. Entonces qué hacía el nene, iba a mi casa. Y mi mamá le hacía la leche, le cortaba el pelo (...) Me acuerdo que nos juntábamos todos los chicos, los padres no le hacían el cumpleaños a él, nosotros hacíamos como un asalto ${ }^{6}$ se llamaba. (Entrevista, mujer, 21 años)

Es así que estos mismos espacios de juego, de encuentro, de compartir y criarse juntos, devienen también espacios, recuerdos, experiencias de dolor. Jugar en la orilla de la contaminación, hacer asaltos y festejos con un amigo -ahora muerto- que como relata a continuación, se cría con dolor por dentro:

\footnotetext{
${ }^{6}$ Asalto es el modo coloquial que reciben en Argentina los primeros bailes que hacen los niños aun en primaria en las casas de los compañeros y/o amigos. Cabe resaltar que es un término que se usa más allá de estos barrios.
} 
Muchos como que no sabían de qué, por qué murió, hasta que después, bueno... lo mató la policía. Y para mí fue triste porque (...) el padre murió de lo mismo y que a él le pasó lo mismo, es triste. Y bueno, es como que tampoco el chico tuvo una contención en su casa, como que la madre también, vamos a decir, lo abandonaba. Y bueno, se crió así, empezó a crecer (...) los vecinos que por ahí lo maltrataban, no lo querían, le decían cosas, 'vos esto, tu papá era tal cosa'. Porque siempre te están juzgando. $\mathrm{Y}$ el nene se crió con mucho rencor... una persona que vos siempre la estás apuntando, le estás diciendo cosas, se cría con un dolor adentro y lo primero que hace, se empieza a vengar o a tener actitudes malas, de violencia. (Entrevista, mujer, 21 años)

Si bien este relato remite a muy diversos aspectos, primero importa resaltar esa cotidianeidad que tenía con su amigo: tomaba la leche en su casa. Y luego continua procurando algún tipo de explicación: como si se tratara de una enfermedad, esta joven relata que el padre también "murió de lo mismo", como algo que a veces pareciera endémico, donde la muerte violenta, ya sea relacionada con el narcotráfico o con el accionar de las fuerzas policiales ${ }^{7}$, como con ese ser apuntado, juzgado, marcara la vida de barrios y sujetos. Esto no debe confundirse con una naturalización de estas muertes, sino más bien refiere a una experiencia temprana con la muerte, que es aquella que traza las líneas de este mapa y se vuelve tangible en las memorias y en los cuerpos.

Asimismo, la joven reflexiona acerca de la vida de los chicos, de las dificultades que a diario viven las familias en estos barrios, de la poca contención que una familia condicionada por la pobreza debe sobrellevar. Al mismo tiempo que señala la mirada abyecta (Grinberg, 2013), acusatoria que muchas veces recae sobre los sujetos y cómo éstos se ven forzados a lidiar con ella. Una mirada que pareciera pensar que este chico eligió la vida y la muerte que le tocó en suerte. Son jóvenes que a través de esas miradas acusatorias son pensados como vidas jugadas de antemano, cuyas muertes, muchas veces violentas y tempranas, aparecen como su horizonte sino más probable por lo menos no sorprendente.

Lo complejo de cartografiar este tejido vital, donde las experiencias más extremas conviven, es que en los relatos si bien aparecen como términos diferenciados (drama y juego, muerte y encuentro, tristeza y recuerdos felices), conviven en las mismas oraciones, compartiendo y haciendo a ese espacio y tiempo. Tanto es así, que es difícil encontrar relatos que refieran a situaciones de juego, donde no aparezca una experiencia dolorosa, ya sea en forma de recuerdo, de temor o de preocupación por que lo vendrá. El siguiente cuento da cuenta de esto:

Había una vez chicos que juegan a la pelota en la cancha de la Carcova. Está muy sucia pero a ellos no les importa y les gusta jugar todos los días. A la noche se pone peligrosa y pasan combis y robaban chicos más chiquitos y mataban y les sacaban los órganos y tripas. En el zanjón mataron a tiros a un pibe que bailaba en la murga. Pasaban pibes con pistolas y empezaban a tirar tiros y los chiquitos estaban jugando en la vereda. (Cuento, mujer, 13 años).

\footnotetext{
7 “Gatillo fácil” es el nombre utilizado comúnmente en Argentina para indicar las muertes causadas por parte de las fuerzas de seguridad. Ver: http://elfederal.com.ar/nota/revista/24237/hay-300-casos-de-gatillo-facil-por-ano http://www.pagina12.com.ar/diario/sociedad/subnotas/77791-25128-2006-12-16.html
} 
El relato de muerte aparece nuevamente en medio del juego. Estos relatos ocurren en ese borde de las políticas sobre la vida en la urbe contemporánea donde, lejos de jóvenes o niños encerrados en sus casas, nos encontramos con chicos que juegan en la canchita, asaltos y bailes de pre-púberes. Hay un vivir en el borde así como un vivir el borde que se realiza en esa tensión de jugar en la vereda mientras de modo intempestivo ocurre un tiroteo; ambos quedan grabados como en la retina.

Ahora, y ligado con el siguiente punto, lejos del desánimo y la desesperanza nos encontramos con jóvenes que luchan y desean, contra todo pronóstico, llegar a "ser alguien". Entre el miedo, la incertidumbre y la tristeza, ellos/as construyen estrategias para eludir aquel horizonte y soñar con una vida mejor. Nuevamente un vivir en el borde, que supone justamente vivir el borde, hacerse parte de él:

Lo que no me gusta es que haya tanta muerte, saber que un chico que lo conociste tantos años o que se crió con vos, esté muerto. A mí me pone mal, es triste (...) Miedo no me da, a la muerte no le tengo. Pero es triste por ahí ver a la madre, el padre que esté llorando por su hijo que lo está velando porque lo mato la policía. Es triste. (Entrevista, mujer, 21 años)

A continuación, entonces, el tercer ítem de la cartografía que aquí proponemos y que remite a la compleja trama que se articula en la posibilidad de ser alguien.

\subsection{Llegar a ser alguien}

Que mi hijo sea alguien, se tiene que esforzar, pero quiero que sea alguien (...) Ser alguien, no sé, ser alguien importante (...) Que estudie, que sea importante, que sea abogado, que sirva para algo. (Entrevista, mujer, 20 años)

La idea de ser alguien, la movilización de ese deseo de ser, aparece recurrentemente en los relatos de los/as jóvenes. Ser alguien ocurre y se realiza con el temor, con la preocupación que genera un presente y un futuro construido en y desde el borde. Como en el epígrafe, ser alguien atraviesa las diferentes generaciones, proyectándose de padres a hijos. En ese fragmento no deja de sorprender que sea una mujer de veinte años quien transfiere esa esperanza a su bebe. En el siguiente fragmento es una joven que remite a las esperanzas que depositaron en ella:

Me di cuenta de que lo único que quiere es que termine, de que tenga un buen futuro y bueno, acá estoy. (Entrevista, varón, 18 años)

De este modo los/as jóvenes, primero en su lugar de hijos, reciben y elaboran ese deseo en sus propias vidas bajo la forma del estudio y el saber, la profesionalización, el obtener un trabajo "digno", vivir nuevas experiencias.

En el relato que abre este apartado, la joven está intentando comenzar sus estudios universitarios proyectando sobre su hijo el deseo de ser alguien. Aquí ser alguien refiere al estudio, a ser importante, a servir para algo. "Ser alguien" cuando conseguir un trabajo bien remunerado y bajo buenas condiciones se presente como muy dificultoso. Esta joven nos habló acerca de su deseo, que se modula entre estudiar y trabajar: 
Estaría bueno hacer las dos cosas. Quiero estudiar porque quiero hacer algo. Estoy cansada de estar todo el día en mi casa, ahí, aparte de cuidar a mi hijo. Estoy todo el día yo sola en mi casa, me aburre estar en casa. Quiero estudiar. Porque a veces cuando estudias te despejas un poco y está bueno. (Entrevista, mujer, 20 años)

Aquí, el estudio remite a otra cosa. No solo se trata de estudiar para tener un mejor trabajo. El estudio es pensado como una posibilidad de dispersión, despejarse; fugar de las preocupaciones que atraviesa la juventud en estos espacios urbanos, incluso de la soledad que se vive al criar un hijo sola. Los padres depositan en sus hijos las esperanzas y deseos que ellos no pudieron alcanzar (terminar los estudios, tener en muchos casos una casa propia, conseguir un mejor trabajo, una mejor calidad de vida, entre otras):

Y yo iba con el pensamiento que siempre mi mamá y mi papá me enseñaron: 'vos tenés que estudiar', y yo iba a estudiar, no iba a hacer otra cosa. (Entrevista, mujer, 21 años)

Probablemente, esto no deje de ser un rasgo común a familias que viven en otros espacios de la urbe, quizá lo específico radique en que se estudia en ese borde que implica vivir en las villas. Asimismo, estudiar se relaciona con la posibilidad de conseguir trabajo, eludir los trabajos considerados más pesados y de poca remuneración. No es llamativo que esta referencia sea hecha por un varón:

Si no estudias... si no tenés un título, no conseguís trabajo. Si no, son trabajos pesados. Conseguís trabajos pesados, te pagan menos también. (Entrevista, varón, 21 años)

"Ser alguien" se convierte por momentos en una especie de carga que los jóvenes llevan en sus espaldas. Y es en ese punto donde estudiar forma parte de la esperanza que tienen para poder tener trabajos otros. Se puede observar cómo los/as jóvenes conocen los prejuicios y las imágenes de criminalización y peligro que pesan sobre ellos y los barrios que habitan. Esta consciencia a veces adquiere la forma de una denuncia hacia su exclusión y donde el estudio deviene así una posibilidad de escapar de la marginación y volverse "alguien" para la sociedad:

Si vos sos alguien te tratan como si fueras alguien, así, de importancia... si tuviste un estudio, una educación... (Entrevista, mujer, 21 años)

Ese te tratan como si fueras alguien si sos alguien parece una tautología. Sin embargo, deja de serlo cuando quien habla es la joven que nació en la villa, que con su amigo -muerto muy joven por la policía- hacía los asaltos y tomaba la leche. Ser alguien es la posibilidad de escapar de la mirada abyecta que pesa sobre estos barrios. Las esperanzas depositadas en el estudio como un medio para mejorar la propia vida, el progreso económico, la posibilidad de conseguir un mejor trabajo y la misma continuidad de sus estudios universitarios, muchas veces son puestas en entredicho. Los jóvenes suelen ser conscientes de las escasas posibilidades que el contexto social en el que viven le brinda para que ello ocurra: 
Algunas personas que me han dicho que la carrera que estoy cursando, dicen que no consigues trabajo, que tengo que tener alguien conocido (...) Un poco me asusta. Porque si, como que me esforcé mucho y si no trabajo de eso, es como que estudié para nada. (Entrevista, mujer, 21 años)

Si bien aparece la duda con respecto a la posibilidad de que el estudio brinde mejor trabajo, esto no significa que estudiar no sea pensado como una apertura al saber y al desarrollo personal. Este "ser alguien" relacionado con el estudio, la profesionalización, el ascenso social, en estos contextos es puesto en tensión en el mismo momento en que se expresa el deseo de estudiar y ser ese alguien. A veces da miedo desear y por eso se desea digamos, prudentemente:

Yo lo veo de la manera que te dije, de la manera de pensar, de abrir la cabeza nada más. No es que terminás la universidad y tenés un trabajo mejor del que tenías antes cuando no estudiabas. Espero que se me dé, lo que se me dé. Y no esperar nada más, no esperar algo más por haber estudiado. (Entrevista, varón, 21 años)

Es en las dificultades cotidianas que se presentan que los jóvenes expresan sus deseos con cautela, como un espacio a conquistar. Lejos de las retóricas que pesan sobre estos barrios, que ubican a los jóvenes de las villas como vidas jugadas, carentes de la posibilidad de proyección, nos encontramos con el deseo, pero no un deseo iluso o romántico, sino un deseo construido a partir del dolor, del amor, de la rabia, de las alegrías y las tristezas que se han hecho carne en sus vidas.

\section{A MODO DE REFLEXIONES FINALES}

A lo largo de este trabajo hemos discutido a través de resultados de investigación, elementos para una cartografía del devenir de la subjetividad en estos espacios de las metrópolis del sur global. Esta tarea la hemos realizado procurando la intersección de un trabajo metodológico que a la vez que involucra largos periodos de estancia en terreno, también es resultado del encuentro de múltiples momentos y puesta en marcha de técnicas de obtención de información y posiciones de investigación que a lo largo de este período hemos asumido. Posiciones que nos han permitido, y aún lo hacen, un contacto permanente con los sujetos, las instituciones y las dinámicas de un barrio en permanente lucha y proceso de hacerse e inventarse. Si esto es válido para cualquier abordaje de la subjetividad, en el caso de los espacios de la urbe en los que nos encontramos trabajando adquiere especial potencia. El barrio, desde la llegada a ese espacio, el movimiento migratorio que lo inicia, la urbanización -desde el agua corriente hasta el relleno del terreno para volverlo habitable-, la construcción de la escuela entre tantos otros aspectos, se realiza y ocurre verbigracia a esa agencia que, individual y colectiva a la vez, puja por tener y hacerse lugar en tiempos en que los mecanismos y relaciones de poder diagraman y cristalizan procesos migratorios, en algunas regiones, masivos.

Agenciamientos, retomando a Deleuze y Guattari (2004), que en su historicidad refieren a los grandes procesos que desde fines del siglo $\mathrm{XX}$ se han traducido en movimientos migratorios permanentes de quienes pierden su lugar y salen a la búsqueda de uno nuevo. En cada relato nos encontramos con esa historia. Pero también con los quiebres, rupturas y re-invenciones que esa agencia trae consigo. Lejos de la mirada abyecta (Grinberg, 2010), 
que suele recaer sobre los barrios y su poblaciones, de las imágenes de los slums como ciudades miseria (Davis, 2007) donde es inimaginable la vida, el deseo y/o su realización, nos encontramos con esos quiebres, con las luchas por hacer y hacerse. El deseo rebasa la vida sin que ello implique negar las propias condiciones en que ese deseo se realiza. Ser alguien es parte de ese hacerse. Cada uno de los barrios porta una pequeña historia, una diferencia, una nota que lo distingue, unas tantas otras bifurcaciones y luchas. Pero también esas luchas suelen guardar notas comunes, en tanto modos de las formas que presenta la biopolítica en la urbe contemporánea. Ambos planos no se oponen ni contradicen sino que se hacen mutuamente $y$, entendemos, ofrecen herramientas para comprender el devenir de la subjetividad en las sociedades contemporáneas.

En este trabajo esbozamos algunas reflexiones acerca de cómo las infancias y juventudes se transitan, se construyen y se relatan por sus protagonistas. Buscar y tener lugar aparece como nota acerca del nacer, llegar/establecerse y criarse en estos barrios, que tienen siempre un registro del moverse y trasladarse como parte del haber perdido y la búsqueda de "su" lugar. Vivir en/el borde remite a algunas de las tensiones propias del vivir en estos espacios, que conjugan juego, miedo, diversión, peligrosidad y que, como observamos, no refieren a términos opuestos, sino a un entramado de experiencias y significaciones que hace a la propia vida en estos barrios. Finalmente, llegar a ser alguien remite a los sueños, los deseos, los temores, que se movilizan y tensionan en torno del presente y el futuro.

Modos de afectar y ser afectado, modos en que los diagramas y la espacialización de las relaciones de poder se cristalizan en las urbes metropolitanas del sur global. Modos de un devenir que involucra las líneas de fuga en tanto que partes de una cotidianeidad que ocurre en el borde y como parte del borde que configuran las biopolíticas de la vida urbana. El despliegue de unas luchas que ocurren y se trazan también en la trama de la subjetividad. Aquí, el trabajo sobre los relatos de infancia se vuelve especial en tanto se mueve en esa historia que a la vez que es personal, que narra ese quién estoy siendo como parte de esa historia quebrada, se compone como la historia de un mundo, de una región, de una país, una ciudad y desde ya un barrio. Es entre esos múltiples relatos que la historia de cada individuo emerge. Y ello cuenta como historización de unas condiciones de vida, pero también como los modos en que los sujetos somos hechos y nos hacemos; somos afectados y afectamos. En esta empresa la realización de una cartografía se vuelve metodológicamente clave, como un modo de acercarse a la comprensión de las tecnologías, la regulación del espacio que conforma nuestra presente urbanidad, el devenir de la subjetivad, trazos y luchas que también ocurren al interior de cada uno/a de nosotros/as.

BUENOS AIRES (ARGENTINA), DICIEMBRE 2015

RECIBIDO: DICIEMBRE 2015 ACEPTADO: MARZO 2016 


\section{REFERENCIAS BIBLIOGRÁFICAS}

ALTHABE G. y HERNÁNDEZ V. (2005). “Implicación y reflexividad”. En: Hernández et al. (comps.), Etnografias Globalizadas. Buenos Aires: Ediciones SAA.

ARABINDOO, P. (2011). "Rhetoric of the 'slum', City: analysis of urban trends, culture, theory, policy, action". Routledge Taylor \& Francis Group, Vol. 15 No6.

AUYERO, J. y BERTI, M. (2013). La violencia en los márgenes. Una maestra y un sociólogo en el conurbano bonaerense. Buenos Aires: Katz Editores.

AUYERO, J. y SWISTUN, D. (2008). Inflamable. Estudio del sufrimiento ambiental. Buenos Aires: Paidós.

AVERSA, M. (2008). "El imaginario legal de una infancia privilegiada: doctrina de derechos y legislación durante los años peronistas: 1946-1955”. En Jornada Historia de la infancia en Argentina, 1880-1960. Enfoques, problemas y perspectivas. Buenos Aires: Universidad Nacional de General Sarmiento.

BILLOROU, M. (2008). "La protección maternal e infantil debe ser colocada en primer plano en un país como el nuestro. Las políticas de protección a la infancia en la Argentina de principios del siglo XX". En Jornada Historia de la infancia en Argentina, 1880-1960. Enfoques, problemas y perspectivas. Buenos Aires: Universidad Nacional de General Sarmiento.

BUSTELO, E. (2007). El recreo de la Infancia. Buenos Aires: Siglo XXI Editores.

CABRERA, P. (2010). "Volver a los caminos andados". En: Revista Nuevas Tendencias en Antropología, No 1 .

CARLI, S. (2002). Niñez, pedagogía y política. Transformaciones de los discursos acerca de la infancia en la historia de la educación argentina entre 1880 y 1955. Buenos Aires: Miño y Dávila.

CARLI, S. (2006). "Notas para pensar la infancia en la Argentina (1983-2001). Figuras de la historia reciente" en Carli, Sandra (Comp.) La cuestión de la infancia. Entre la escuela, la calle y el shopping. Buenos Aires: Editorial Paidós.

CASTILLO-GALLARDO, P. (2015). "Desigualdad e infancia: lectura crítica de la Historia de la Infancia en Chile y en América Latina”. Revista Latinoamericana de Ciencias Sociales, Niñez y Juventud, Vol. $13 \mathrm{~N}^{\mathrm{o}} 1$.

COLE, D. (2013). "Lost in data Space: using nomadic analysis to perform social science", in B. Coleman y J. Ringrose (ed.), Deleuze and Research Methodologies. Edinburgh: Edinburgh University Press.

COSSE, I. (2005). "La infancia en los años treinta. Innovaciones en las políticas públicas". En revista Todo es Historia, $\mathrm{N}^{\mathrm{o}} 457$.

COWEN, P. (2000). "Nacimientos, partos y problemas de la primera infancia. Fines del siglo XVIII, primeras décadas del siglo XIX”. En Moreno, José Luis (Comp.). La política social antes de la política social (caridad, beneficencia y política social en Buenos Aires, siglos XVII a XX). Buenos Aires: Trama / Prometeo.

CRAVINO, C. (1999) "Los asentamientos del Gran Buenos Aires. Reivindicaciones y contradicciones". En Neufeld, M., Tiscornia, S., Grinberg, M. y Wallace, S. (Ed.). Antropología social y económica. Hegemonía y poder: El mundo en movimiento. Buenos Aires: Eudeba.

CURUCHET, G., GRINBERG, S. y GUTIÉRREZ, R.(2012).“Degradación ambiental y periferia urbana: Un estudio transdiciplinario sobre la contaminación en la Región Metropolitana de Buenos Aires.” En Ambiente \& Sociedade Vol. 15 No. Sao Paulo. 
CHOI, J. (2006). "Doing poststructural ethnography in the life history of dropouts in South Korea: methodological ruminations on subjectivity, positionality and reflexivity", in International Journal of Qualitative Studies in Education Vol. 19, № 4.

DAS, V. (2003). "Trauma and Testimony. Implications for political community". En: Anthropological Theory. Vol. 3.

DAROQUI, A., CALZADO, M., MAGGIO, N. y MOTTO, C. (2007). "Sistema penal y derechos humanos: la eliminación de los "delincuentes". Una Mirada sobre las prácticas y los discursos de la policía, la justicia y los medios de comunicación". En Revista Espacio Abierto, Vol. 16, №03.

DAVIS, M. (2007). Planeta de ciudades miseria. Madrid: Foca.

DELEUZE, G. y GUATTARI, F. (2004). Mil Mesetas. Valencia: Pre-Textos.

DELEUZE, G. (2007). Pericles y Verdi. Valencia: Pre-textos.

DUARTE-DUARTE, J. (2013). "Infancias contemporáneas, medios y autoridad". Revista Latinoamericana de Ciencias Sociales, Niñez y Juventud, Vol. 11 №2.

FOUCAULT, M. (2001). "El sujeto y el poder", en Dreyfus y Rabinow, Michel Foucault: más allá del estructuralismo y la hermenéutica. Buenos Aires: Ediciones Nueva Visión.

FOUCAULT, M. (1999). Historia de la sexualidad 1-La voluntad de saber. México: Editorial Siglo XXI.

FOX, N. y ALLDRED, P. (2015)."New materialist social inquiry: designs, methods and the research-assemblage". En International Journal of Social Research Methodology, Vol. $18 \mathrm{~N}^{\circ} 4$.

GENTILE, M. (2007). "La interacción cotidiana en un centro para niños y adolescentes en situación de calle, desde la experiencia de los chicos que participan". $1^{\circ}$ Reunión Nacional de Investigadores/as en Juventudes (RENIJ). Universidad Nacional de La Plata.

GÓMEZ-MENDOZA, M. y ALZATE-PIEDRAHÍTA, M. (2014). "La infancia contemporánea". Revista Latinoamericana de Ciencias Sociales, Niñez y Juventud, Vol. $12 \mathrm{~N}^{\mathrm{o}} 1$.

GRIGNON, C. y PASSERON, J. (1991). Lo culto y lo popular: miserabilismo y populismo en la sociología y en la literatura. Buenos Aires: Nueva Visión.

GRINBERG, S. (2008). Educación y poder en el siglo XXI. Gubernamentalidad y pedagogía en las sociedades de gerenciamiento. Buenos Aires: Ed. Miño y Dávila.

GRINBERG, S. (2010). "Pedagogía y políticas sobre la vida en la sociedad de empresa: entre el gerenciamiento y lo abyecto. Relatos de racionalidad fragmentada", en Biopoliticas del Sur. Santiago Chile: Editorial Universidad Arcis.

GRINBERG, S. (2011) "Territories of Schooling and Schooling Territories in Argentinean Extreme Urban Poverty Contexts". En Emotion, space and society, Vol.4 N³. Londres: Elsevier.

GRINBERG, S., GUTIÉRREZ, R. y MANTIÑÁN, L. (2012). "La comunidad fragmentada: Gubernamentalidad y empoderamiento en territorios urbanos hiperdegradados". En Revista Espacios nueva serie, Estudios de Biopolítica N$^{\circ}$ 7. UNPA Universidad Nacional de la Patagonia Austral.

GRINBERG, S. (2012). "Escuela, producción audiovisual y subjetivación en contextos de extrema pobreza urbana. Notas de banalidad cotidiana». En Polifonías No 1. Luján: UNLU.

GRINBERG, S. (2013). "Pedagogía de las competencias y gubernamentalidad en las 
sociedades de gerenciamiento. La formación: entre la reinserción y la abyección.” Revista textos. Bogotá: Pontificia Universidad Bolivariana de Medellín. Vol. $8 \mathrm{~N}^{\circ} 18$.

GRINBERG, S. y LANGER, E. (2014). "Struggling For Knowledge in Times of Cognitive Capitalism: Youth and School in Contexts of Urban Poverty". Knowledge Cultures Vol. 2. New York.

GRINBERG, S. y DAFUNCHIO, S. (2016). "Screaming Silences Subjects and photographs in schools in contexts of extreme urban poverty and environmental decay", en Cole (ed.) Dimensions in Globalization and Education. New York: Springer.

GROPPO, L. (2015). "Teorias pós-críticas da juventude: juvenilização, tribalismo e socialização ativa". Revista Latinoamericana de Ciencias Sociales, Niñez y Juventud, Vol. $13 \mathrm{~N}^{\circ} 2$.

GUBER, R. (2001). La etnografía. Método, campo y reflexividad. Bogotá: Grupo Editorial Norma.

HICKEY-MOODY, A. (2013). Youth, Arts, and Education: Reassembling Subjectivity through Affect. New York: Routledge.

IERULLO, M. (2015). "La crianza de niños, niñas y adolescentes en contextos de pobreza urbana persistente". Revista Latinoamericana de Ciencias Sociales, Niñez y Juventud, Vol. $13 \mathrm{~N}^{\circ} 2$.

LEWIS, O. (1983). La vida. Barcelona: Grijalbo.

LITICHEVER, C. (2009). Trayectoria Institucional y Ciudadanía de Chicos y Chicas en Situación de Calle. Maestría en Diseño y Gestión de Programas y Políticas Sociales. Tesis inédita. FLACSO.

LLOBET, V. (2009). ¿Fábricas de niños? Las instituciones en la era de los derechos. Buenos Aires: Editorial Novedades Educativas.

LLOBET, V., GERARDI, F. y PIATELLI, A. (2002). "Representaciones y prácticas en las instituciones para la infancia vulnerabilizada". En Investigaciones en Psicología, Año 7, ํ⒊ Revista del Instituto de Investigaciones de la Facultad de Psicología, UBA.

MACRI, M. y FORD, M. (2005). El trabajo infantil no es un juego. Buenos Aires: Editorial La Crujía.

MALLIMACI, F. y GIMÉNEZ BÉLIVEAU, V. (2006). "Historia de Vida y métodos biográficos". En Irene Vasilachis de Gialdino (coord.). Estrategias de Investigación Cualitativa. Buenos Aires: Gedisa.

MARCUS, G. (2001). "Etnografía en/del sistema mundo. El surgimiento de la etnografía multilocal". Alteridades Vol.11 No22.

MATEOS, P. (2006). "Trayectorias y aprendizajes sociales de chicas y chicos en situación de calle". En Carli, Sandra (Comp.). La cuestión de la Infancia. Entre la escuela, la calle, el shopping. Buenos Aires: Paidós.

MERKLEN, D. (2005). Pobres ciudadanos. Las clases populares en la era democrática (Argentina, 1983-2003). Buenos Aires: Ed. Gorla.

MINUJIN, A., DELAMONICA, E. y DAVIDZIUK, A. (2006). "Pobreza Infantil: Conceptos, Medición y Recomendaciones de Políticas Públicas". Cuaderno de Ciencias Sociales 140. Facultad Latinoamericana de Ciencias Sociales (FLACSO), Sede Académica Costa Rica.

OSBORNE, T. y ROSE, N. (1999). "Governing Cities: Notes on the Specialization of Virtue", Environmental and Planning D, Society and Space Vol. 17.

PEIRANO, M. (1995). A favor da etnografía. Río de Janeiro: Relume Dumará. 
POJOMOVSKY, J., CILliS, N. y GENTILE, M. (2008). Cruzar la calle, niñez y adolescencia en las calles de la ciudad. Buenos Aires, Argentina: Espacio editorial.

PREVOT-SCHAPIRA, M. (2001). "Fragmentación espacial y social: Conceptos y realidades". En Perfiles Latinoamericanos, Nº19.

RAMÍREZ- LÓPEZ, N. (2014). "Narrativas de vida y memorias: conflicto escolar en el Colegio Santa Librada". Revista Latinoamericana de Ciencias Sociales, Niñez y Juventud, Vol.12 Nº1.

RATIER, H. (1985). Villeros y villas miseria. Buenos Aires: Centro Editor de América Latina.

RINGROSE, J. y COLEMAN, R. (eds.) (2013). Deleuze and Research Methodologies. Edinburgh: Edinburgh University Press.

ROCKWELL, E. (2009). La experiencia etnográfica. Historia y cultura en los procesos educativos. Buenos Aires: Paidós.

ROMERO, J. L. (1986). Latinoamérica: Las ciudades y las ideas. Buenos Aires: Siglo Veintiuno Editores.

ROSE, N. (2007). The politics of life itself. USA: Princeton University Press.

ROY, A. (2011). "Slumdog Cities: Rethinking Subaltern Urbanism". En International Journal of Urban and Regional Research. Vol. $35 \mathrm{~N}^{\circ} 2$.

SARAVÍ, G. (2006). "Biografías de Exclusión: desventajas y juventud en Argentina”. En Perfiles Latinoamericanos $\mathrm{N}^{\mathrm{o}}$ 028. Distrito Federal, México: Facultad Latinoamericana de Ciencias Sociales.

SCHEPER-HUGHES, N. (1993). La muerte sin llanto. Violencia y vida cotidiana en Brasil. Barcelona: Ed. Ariel.

YOUDELL, D. (2006). Impossible Bodies, Impossible Selves: Exclusion and Student Subjectivities. Netherlands: Springer.

ZAPIOLA, M. (2008). "La Ley de Patronato de 1919: una reestructuración parcial de los vínculos entre Estado y "minoridad". En Jornada Historia de la infancia en Argentina, 1880-1960. Enfoques, problemas y perspectivas. Buenos Aires: Universidad Nacional de General Sarmiento. 